\title{
Monitoramento da informação e inteligência competitiva: realidade organizacional
}

\author{
Information monitoring and competitive intelligence
}

\begin{abstract}
Wanda Aparecida Machado Hoffmann
Pós-Doutorado em Prospecção de Informação Tecnológica pela Universidade Federal de São Carlos, UFSCar. Docente do Departamento de Ciência da Informação e do Programa de Pós-Graduação em Ciência, Tecnologia e

Sociedade da UFSCar.

E-mail: wanda@nit.ufscar.br
\end{abstract}

\section{Resumo}

Este estudo envolve a compreensão do monitoramento da informação (MI) e da inteligência competitiva (IC), mas, principalmente, buscando refletir em como superar os múltiplos desafios organizacionais, voltado para a informação e o conhecimento. A gestão da informação e do conhecimento, bem como, a IC constituem uma nova abordagem para o planejamento e a administração estratégica das organizações, fortalecendo o seu processo de tomada de decisão. A interdependência resultante da globalização e o surgimento do que se convencionou chamar "sociedade do conhecimento", e também a aceleração decorrente das tecnologias da informação e comunicação (TIC) impactaram e tiveram consequiências sobre as organizações, ocasionando mudanças nos métodos de trabalho, produção, pesquisa e de utilização dos dados e informações. Assim, com o advento das novas relações econômicas, tanto nacionais quanto internacionais, e de um novo paradigma tecnológico, baseado, por exemplo, na produção flexível, as organizações se depararam com uma competição acirrada e um volume de dados e informações gigantescos. Esse processo está gerando, de um lado, uma crescente imprevisibilidade dos mercados e de outro, o encurtamento do ciclo de vida das tecnologias de produtos e processos. As organizações precisam reconstruir diariamente sua capacidade competitiva, para fazer frente aos riscos de entrada de novos concorrentes, às mudanças nos padrões de consumo, ao surgimento de novas tecnologias de produto e processo, etc. Nesse contexto de competição acirrada e o bombardeio constante de informações, devido ao processo de democratização da comunicação e do aumento do número de canais de mídia disponíveis, o MI e a IC surgem como uma das possíveis maneiras de conduzir e planejar movimentos para traçar cenários no ambiente organizacional. Muitas vezes, as organizações são pródigas em acumular informações, mas não sabem o que fazer com elas. Mas, as decisões devem ser tomadas para manter a empresa alinhada aos seus objetivos pretendidos, com base nas informações adequadas de interesse do seu negócio, induzindo a se buscar posturas organizacionais proativas, com posicionamentos da organização fortalecidos sobre seu ambiente informacional e organizacional, buscando um acerto diante das diversas alternativas desses ambientes.

Palavras-chave: Monitoramento da informação; Inteligência competitiva; Ambiente organizacional

\begin{abstract}
This study involves the understanding of the monitoring information (MI) and competitive intelligence (CI), but mainly trying to reflect on how to overcome the many organizational challenges, focusing on information and knowledge. Managing information and knowledge, as well as the IC is new approaches to planning and strategic management of organizations, strengthening their decision-making process. The interdependence resulting from globalization and the emergence of so-called "knowledge society", and also due to the acceleration of information and communication technologies (ICT) impacted and had consequences for organizations, leading to changes in working methods, production, research and use of data and information. So with the advent of new economic relations, both domestic and international, and a new technological paradigm based on, for example, in flexible production organizations were faced with stiff competition and a volume of data and information giant. This process is generating on the one hand, an increasing unpredictability of the markets and the other, shortening the life cycle of technology products and processes. Organizations need to rebuild their competitiveness in a daily basis, to face the risk of new competitors, changes in consumption patterns, the
\end{abstract}

InCID: R. Ci. Inf. e Doc., Ribeirão Preto, v. 2, n. 2, p. 125-144, jul./dez. 2011. 
emergence of new product and process technologies. In this context of fierce competition and constant bombardment of information, due to the democratization of communication and the increasing number of media channels available, the MI and CI emerge as one of the possible ways of conducting and planning scenarios to trace movements in the organizational environment. Very often, organizations are lavish in accumulating information, but do not know what to do with them. But decisions must be taken to keep the company aligned with its intended goals, based on interesting adequate information to the business, leading to pursue proactive organizational positions, with positions on the organization strengthened by its organizational and informational environment, seeking an accuracy of the various alternatives facing these environments.

Keywords: Monitoring information; Competitive intelligence; Organizational environment

\section{O Ambiente informacional}

A abrangência do ambiente informacional ocorre justamente em um contexto atual em que as transformações mais revolucionárias ocorrem nas técnicas e métodos de como lidar com a informação, ou seja, em como acessar, coletar, tratar e analisar a informação. No ambiente informacional existe uma proposta de utilização, como simples analogia com a biologia ou mais exatamente com a ecologia ${ }^{1}$ a chamada "Ecologia da Informação". Essa denominação tem sido recebida e trazida ao ambiente informacional e organizacional por ter características que são encontradas no estudo da ecologia. Esses estudos envolvem a observação e descrição de ambientes, a integração dos diferentes tipos de informação, a descrição e observação da informação e dos processos informacionais. A ênfase no comportamento individual e coletivo com relação à informação, e no reconhecimento de mudanças evolutivas no ambiente informacional. Davenport (2001) definiu o conceito "ecologia da informação" e descreveu três ambientes relevantes para informação e o conhecimento organizacional: ambiente informacional; ambiente organizacional e ambiente externo à organização.

O ambiente informacional é o núcleo da nossa abordagem e subdividido em: processo informacional, política informacional, estratégia informacional, comportamento e cultura informacional e, arquitetura informacional.

O processo informacional envolve a execução do trabalho, como toda a atividade é exercida por quem trabalha com a informação. A política informacional define as diretrizes para o gerenciamento e uso das informações. A estratégia informacional define os tipos de informação a serem priorizados e os passos do seu gerenciamento, bem como a informação que será útil. O comportamento e cultura informacional são relacionados: a) ao

\footnotetext{
${ }^{1}$ A ecologia, segundo Ferreira (2002), é a parte da Biologia que estuda as relações entre os seres vivos e o meio ou ambiente em que vivem, bem como suas recíprocas influências.
}

InCID: R. Ci. Inf. e Doc., Ribeirão Preto, v. 2, n. 2, p. 125-144, jul./dez. 2011. 
comportamento referente à forma como a pessoa lida com a informação, ou seja, como ela busca, coleta, utiliza, cria, altera, acumula, distribui, valoriza e estabelece atitudes com relação à informação; b) a cultura que representa os valores e crenças de uma pessoa ou grupo, em relação à informação, descreve o padrão de comportamento e atitudes que expressam a orientação informacional de uma pessoa ou organização. A arquitetura informacional compreende o conjunto de recursos utilizados para o atendimento das necessidades do trabalho com a informação, como softwares, hardware, diretórios, documentos, profissionais especializados, etc. A arquitetura da informação é o elo entre o comportamento, processos e indivíduos com a estrutura organizacional, espaço físico e métodos de gestão.

Assim, nas organizações, públicas e privadas, ocorre a valorização da informação, a maior parte do tempo se busca a informação que possa ser útil, que possa reduzir a incerteza sobre os problemas e sobre as melhores maneiras de resolvê-los e as melhores decisões a tomar. Pois, a compreensão do papel do ambiente informacional passa, necessariamente, pela análise dos processos de transformação que vêm ocorrendo a partir das grandes mudanças sociais, econômicas, tecnológicas, políticas e culturais (NAISBITT, ABURDENE, 1990).

A superoferta de informação induz a pensar no grande volume de informações existentes e seu contínuo aumento, como, por exemplo, nos elevados números de publicações (livros, revistas científicas, artigos, patentes, etc.) que existem e surgem a cada ano, bem como os também elevados números de documentos da Internet, como as bases de dados, os documentos eletrônicos integrais, as centenas de ferramentas de busca, etc., que existem e surgem significativamente a cada dia. Existe um repertório de informações que estão disponíveis na Internet, públicas ou privadas, que fazem parte do ambiente informacional e que envolvem o ambiente organizacional, como, por exemplo: pesquisa de mercado, estudos setoriais e mercadológicos, séries históricas de variáveis econômicas, imprensa diária, especializada e de negócios, boletins e relatórios empresariais, feiras e reuniões setoriais, informações sobre produtos, preço e posicionamento, tendência tecnológica, líderes de opinião e especialistas, boletins informativos, informações sobre concorrentes, informações sobre clientes, base de dados científicas, tecnológicas e de negócios, artigos técnicos, patentes, normas técnicas, entre outros. Nesse contexto, de superoferta de informação, para não se ter a sensação de impotência frente a esse grande volume de informação, principalmente em como acessá-lo e usá-lo, a forma encontrada para lidar com isso é por meio do uso adequado das TIC, que estão acompanhando e, de certa forma, induzindo a esse crescimento informacional. Esse uso adequado é possível com a integração de diversas TIC InCID: R. Ci. Inf. e Doc., Ribeirão Preto, v. 2, n. 2, p. 125-144, jul./dez. 2011. 
envolvendo textos, imagens e sons. Essas TIC possibilitam uma interação dinâmica com o usuário e entre usuários como e-mail, e-commerce, e-business, e-book, e-life, etc.

\section{Ambiente organizacional}

O ambiente organizacional é compreendido como a integração de todas as condições, fatos, eventos e influências que envolvem e interagem no contexto da organização, incluindo o seu ambiente externo e interno. O ambiente interno é o nível de ambiente da organização que está inserido na organização, como: as pessoas, processos, produtos, serviços, atendimento, capital, tecnologia, normas, procedimentos, máquinas, equipamentos, móveis, instalações, estrutura organizacional, materiais, cultura organizacional, entre outros. O ambiente externo compreende: clientes, usuários, fornecedores, distribuidores, concorrentes, governo, meio ambiente, legislação, mercado financeiro, mercado tecnológico, mercado de mão de obra, associações, sindicatos, consumidores, investidores, entre outros. O ambiente organizacional pode ser ilustrado por um modelo que envolve o gerenciamento da informação, como estudado por Davenport (2001), e mostrado na Figura 1. O ambiente organizacional é envolvido pelo ambiente informacional com seus elementos e pelo ambiente externo e de negócios. Esses ambientes se interconectam, sendo necessário compreender todo o cenário para uma analise ambiental, inclusive para identificar fatores como a estabilidade ou a turbulência do ambiente.

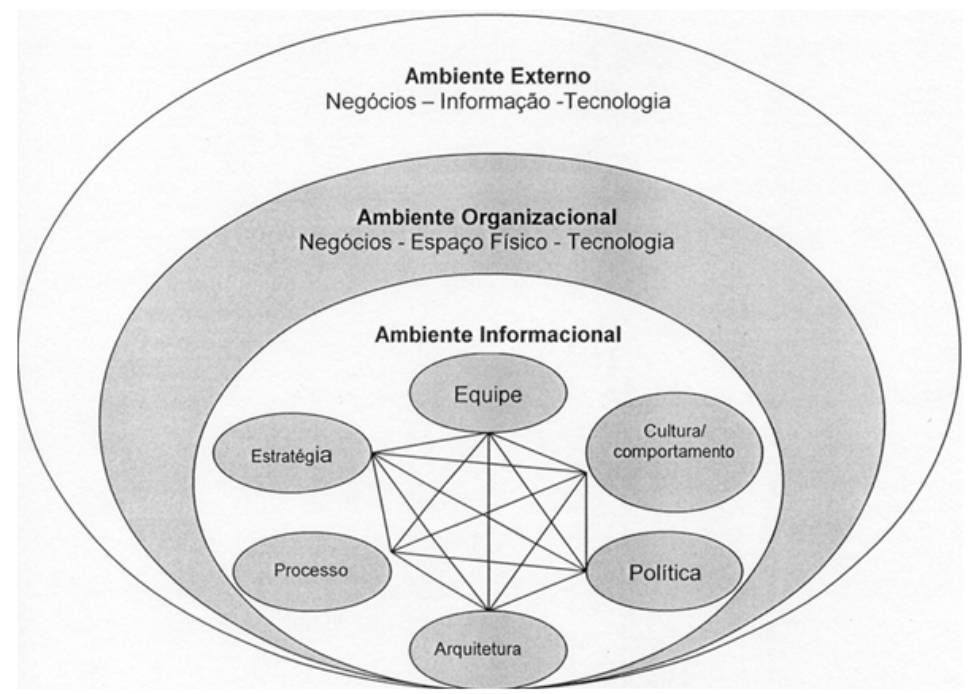

Figura 1. Modelo para o gerenciamento da Informação. Adaptado de Davenport (2001) 


\section{As mudanças ocorridas nas organizações e nos consumidores}

As mudanças nas organizações foram ocorrendo à medida que a sociedade foi se desenvolvendo, acompanhando os contínuos aperfeiçoamentos e necessidades de cada época. O modelo organizacional delineado no século XX, a partir dos anos de 1920, impôs uma produção em massa, escala de produção, sincronizada, concentrada, maximizada, é a chamada era do taylorismo, representada pela produção em massa, por exemplo, do carro marca Ford. Nesse período, as empresas caracterizavam-se por contextos hierarquizados e de alta especialização do trabalho, perfil, da era industrial. A seguir surge uma nova atitude gerencial calcada nos recursos humanos (1950), em que o homem é considerado um dos fundamentais elementos para o sucesso das organizações, promovendo uma mudança nas relações de trabalho. Por volta dos anos de 1970, as organizações se deparam com a competição acirrada e, assim, começa a tomar significância a busca por ampliar os mercados ou conquistar novos, satisfazendo as necessidades desse mercado, o foco das organizações se volta para o mercado. Nos anos 1980, surge uma nova orientação para as organizações se manterem competitivas. É a era da qualidade ou "qualidade total", proposta pelos japoneses, em que padrões, normas, certificações, entre outros, são atitudes de todos os envolvidos nas empresas, com vista ao cliente. As mudanças vão se propagando no ambiente organizacional, chegando aos anos de 1990 num cenário de acelerada transformação e desenvolvimentos tecnológicos, a tecnologia é o foco. Nesse momento surgem as novas formas de corporações, que incluem parcerias estratégicas e redes organizacionais, além do acirramento da concorrência, os rápidos avanços das TIC e, principalmente, a globalização da economia, que são catalisadores no desenho do novo ambiente organizacional e de seus negócios (CHIAVENATO, 2000; WEBSTER, 1992).

O ambiente organizacional chega ao novo século XXI, caracterizado por muitas e rápidas mudanças, antes embasado em tecnologias intensivas em capital, energia e processos de produção, e com as transformações, a ênfase passa para as tecnologias intensivas em informação, flexíveis e computadorizadas. O novo modelo organizacional apresenta-se descentralizado, no qual os funcionários participam das decisões da organização, existe um maior espírito de cooperação, materializado em nova atitude gerencial, calcada na formação de redes de fornecedores, clientes e entre organizações concorrentes. O mercado, com crescente atendimento às necessidades do cliente, mas com melhoria contínua dos processos produtivos, e intensificação do fluxo de informações, baseado principalmente em TIC.

A nova realidade das organizações frente à chamada era da informação e do conhecimento, requer a reorganização das suas ações e procedimentos. Assim, o foco voltado InCID: R. Ci. Inf. e Doc., Ribeirão Preto, v. 2, n. 2, p. 125-144, jul./dez. 2011. 
ao papel da informação que atua como um agente detonador de mudanças na economia, na política, nos processos produtivos e até nas relações de trabalho, impõe às organizações a necessidade de maior esforço em se estruturar, agregar mais competência e ter agilidade decisória (BORGES, 1995). Nesse contexto, o cenário das estratégias produtivas e mercadológicas é composto pelo conhecimento criado a partir das informações e do processo de inteligência que vai integrar todo o ambiente informacional para se converter em ações específicas, e com valor agregado ao ambiente organizacional, levando as organizações a atingirem, amplamente, seus objetivos e metas a que se propõem.

Assim, a mudança de comportamento das organizações é proveniente do seu meio ou mercado, pois com o mercado globalizado, caracterizado por ausência de fronteiras, produtos sem nacionalidade, diferenças culturais, etc., levam a novas diretrizes para a atuação organizacional, valorizando significativamente aspectos técnicos e de qualidade, os aspectos ambientais e, principalmente, o respeito ao consumidor ou usuário e as suas necessidades.

Também a mudança de comportamento das organizações ocorreu pelas mudanças que o consumidor sofreu, pois com a maior oferta de produtos, a concorrência entre produtos, ele tornou-se mais exigente, mais seletivo e mais maduro. Com isso, as organizações se deparam com situações ou problemas mais complexos, verdadeiros desafios para satisfazer seus consumidores e os manter, frente à grande concorrência entre as organizações.

Os resultados dessa aceleração da produção obrigam as organizações a conviver com ciclos de vida mais curtos de produto ou serviço, maior número de financiamentos e movimentação de recursos, padrões de consumo mais efêmeros, mais negociações, mais mudanças nos preços, e também mais dependência de informações, ou seja, surgem os múltiplos desafios organizacionais.

Os desafios organizacionais são muitos e diversos, envolvendo o ambiente dos negócios da organização que disponibiliza no mercado produtos e serviços. A organização, para desempenhar seu papel, precisa gerenciar diversos elementos como pessoas, materiais, design, etc. Nesse contexto, surgem os desafios técnicos ou operacionais, os gerenciais e os estratégicos. No seu ambiente externo, caracterizado pelo mercado, a organização encontra desafios ao lidar com concorrentes, fornecedores, consumidores, usuários, créditos, etc., além do macro ambiente envolvendo questões econômicas, sociais, políticas, ecológicas, regulatórias e tecnológicas. Ainda seus desafios são em âmbito nacional e internacional ou global.

A grande questão que se apresenta para as organizações é em como superar esses desafios. Com isso, surge o MI e o uso de métodos inovadores de se trabalhar com a InCID: R. Ci. Inf. e Doc., Ribeirão Preto, v. 2, n. 2, p. 125-144, jul./dez. 2011. 
informação, como a IC, que possibilita compreender as atividades da concorrência, as tendências setoriais, o mercado em geral e a macroeconomia, etc. Também, possibilita de forma adequada, planejar, organizar, alocar recursos (humanos, informacionais, financeiros, tecnológicos, naturais), controlar, dirigir, liderar e motivar as pessoas, ou seja, investir esforços para atingir seus objetivos.

O foco de atenção das organizações é centrado no ambiente competitivo e envolve: a) a capacidade de absorver e gerar informação, para orientar as estratégias de negócios, tanto em relação a tecnologia ou mercado, na condução de soluções próprias; b) o foco no consumidor ou usuário, com a tradução de desejos e expectativas em produtos e serviços; c) o uso de métodos de gestão, para possibilitar o aumento de produtividade, a melhoria contínua, a redução de variabilidades, a valorização e crescimento do ser humano, a criatividade, a polivalência e flexibilidade, o processo decisório participativo e os resultados compartilhados.

\section{Monitoramento da informação e Fundamentos de Inteligência Competitiva}

Cada vez mais os gestores estão se apoiando em métodos, técnicas e práticas que envolvem o uso e análise de informações para vencerem os desafios da nova economia ou do ambiente organizacional atual. Assim, o MI e a IC, são possibilidades ou alternativas importantes para os gestores e suas organizações, pois atuam buscando compreender os acontecimentos do ambiente organizacional. Esses acontecimentos surgem no horizonte organizacional de diferentes formas, por exemplo, com o surgimento de novas tecnologias, novos negócios, novas formas de trabalho, novos processos, novos materiais, entre outros, que modificam o cenário do ambiente organizacional.

Muitos gestores acreditam que ter as informações corretas é a chave para o sucesso, frente às mudanças organizacionais (downsizing ${ }^{2}$, redução de staff $^{3}$, fusões, aquisições, etc.), alteração no foco do negócio (regionalização, alianças estratégicas, operações estratégicas, operações "virtuais", integração com clientes, etc.), globalização (difusão de recursos, aumento das complexidades, questões de comunicação, padronização de desafios, etc.), quebra de confiança nas TIC, ou ainda falhas de implementação, benefícios não alcançados de automação, sobrecarga de informações, etc. Entretanto, para conseguir essas informações

\footnotetext{
${ }^{2}$ Downsizing é uma expressão, em inglês, que significa reduzir o tamanho da empresa, especialmente no numero de empregados e no numero de níveis hierárquicos na estrutura organizacional, para reduzir seus custos e aumentar a sua flexibilidade e adaptabilidade.

${ }^{3}$ Staff é uma expressão, em inglês, que significa corpo de assistentes ou equipe de auxiliares, designam funções de assessorias aos gestores da empresas/organizações.
}

InCID: R. Ci. Inf. e Doc., Ribeirão Preto, v. 2, n. 2, p. 125-144, jul./dez. 2011. 
corretas é necessário um investimento dos gestores e suas organizações em se capacitarem quanto ao uso de métodos e técnicas adequados de acesso, coleta, análise e uso da informação, como os métodos e técnicas de MI e IC.

O MI faz parte do processo de IC, pois através do monitoramento é possível estabelecer um quadro ou mapa inicial de fontes de informação e conhecimento essenciais ao negócio da organização. O mapeamento de dados, informação e conhecimento, alimenta ou atua como matéria prima para as aplicações de IC, estabelecendo uma dinâmica de entrada dos dados e informações no seu processo de atuação.

\section{Fundamentos do monitoramento da informação}

O MI é o método ou técnica de observação e acompanhamento sistemático e constante de dados, informação e conhecimento relevantes ao negócio da organização. $\mathrm{O}$ monitoramento trabalha como um radar, orientado para detectar e interpretar os sinais do ambiente relativos a organização. Segundo Tarapanoff (1995), o termo monitoramento tem origem na corrente americana, similar a corrente francesa veille (vigília), e que designa uma técnica que tem como característica principal a observação e coleta de fatores científicos, tecnológicos, econômicos, sociais e outros que possam afetar e impactar a organização.

O termo monitoramento é empregado em português, além de monitoramento, também prospecção, vigília, etc. Em inglês, os termos utilizados para monitoramento são: Forecast(ing), Foresight(ing), Assessment, Future Studies, Technological Watch, etc. Em francês, os termos utilizados são: prospective, futuribles, etc.

$\mathrm{Na}$ literatura, são descritos alguns princípios para a prática de MI, como por exemplo, o Choo (apud MORESI, 2001), que descreve alguns desses princípios como:

- Planejar e gerenciar a monitoração como atividade estratégica, como um programa de pesquisa e desenvolvimento;

- Implementar a atividade como um sistema formal, planejado, contínuo e coordenado;

- Estabelecer parcerias com especialistas em tecnologia da informação em projetar sistemas de monitoração, especialistas em determinados temas ou assuntos e peritos em informação;

- Gerenciar a informação como uma função básica da monitoração.

InCID: R. Ci. Inf. e Doc., Ribeirão Preto, v. 2, n. 2, p. 125-144, jul./dez. 2011. 
O monitoramento é uma atividade de visualização e busca da informação no interior de determinados contextos do ambiente organizacional, e também inclui uma quantidade de atividades pessoais e organizacionais. Assim, o processo de monitoramento do ambiente entendido como esforço, no sentido de acompanhar, interpretar e compreender a natureza das mudanças, que ajudam a definir uma linha de ação futura da organização, é desafiante (CHOO, AUSTER, 1993). O monitoramento é um processo de filtragem de um grande volume de informações para alguma necessidade, atendendo a critérios específicos. Esses processos têm alguns passos (adaptado de TARAPANOFF, 2001): procura por recursos de informação; seleção dos recursos de informação; identificação dos critérios de monitoramento; execução do monitoramento; determinação das ações a serem tomadas, em face dos resultados do monitoramento e a avaliação e registro do processo de monitoramento.

São considerados vários os tipos de MI, sendo alguns mencionados, como monitoramento ambiental; dos concorrentes; tecnológico; político-econômico e financeiro.

O monitoramento ambiental considera todos os fatores externos que poderão influir no desempenho de uma organização, assim como a manutenção e/ou sobrevivência do seu negócio. Para Choo (apud MORESI, 2001), a monitoração de ambientes organizacionais é a aquisição e uso de informação sobre eventos, tendências e relações em seu ambiente externo, cujo conhecimento auxiliará os gestores a planejar e executar as futuras ações ou tomadas de decisão. As mudanças, os eventos e as oportunidades no ambiente, de modo contínuo, criam sinais e mensagens. Após esses sinais ou mensagens serem detectadas e transformadas em informações são utilizadas pelas organizações para se adaptarem às novas condições e tomarem melhores decisões, aumentando seu desempenho. Assim, de um grande número de informações, faz-se necessário identificar aquelas que têm potencial relevância, funcionando como uma antena na identificação de novas oportunidades e sinais de mudança no ambiente.

O monitoramento dos concorrentes analisa e acompanha as trajetórias, rotas estratégicas, desempenho e posicionamento competitivo dos concorrentes atuais e potenciais. A função do monitoramento dos concorrentes é seguir ou monitorar determinantes ou elementos de competitividade, assim como realizar análise dos concorrentes atuais e potenciais, além de produtos substitutos, processos mais adequados, entre outros. Sua finalidade é a observação desses concorrentes, o destino de seus produtos, distribuição dos produtos, tipos de clientes e grau de satisfação, cadeia de valor do setor, forças existentes ou potenciais no mercado, influências da economia, regulamentação, política, etc. Para 
Stollenwerk (2000), considera-se que corresponde à análise de duas forças de Porter ${ }^{4}$ : ameaça de novos entrantes e rivalidade entre os concorrentes.

O monitoramento tecnológico é acompanhar os avanços técnicos e científicos, obter a inovação de produtos existentes, criar novos produtos, examinar as questões oriundas da convergência tecnológica, assim como as possibilidades de fusões e aquisições para reduzir questões de apropriação de tecnologia, ou seja, colocar a organização em estado de alerta.

A estruturação de um processo de monitoramento tecnológico é uma necessidade crescente das organizações que competem em mercados dinâmicos e globalizados. Conseguir acompanhar as mudanças principalmente as tecnológicas nas suas áreas de atuação nacional e internacional, entender as consequências e tomar as decisões e ações adequadas é desafiante para as organizações, e requer a uma estruturação dos seus processos de monitoramento.

Monitoramento tecnológico é afetado mais imediatamente pelas consequências econômicas da inovação tecnológica. Assim, uma das alternativas é o monitoramento tecnológico, na busca de identificar as inovações, que ocorrem por meio de documentos técnicos como patentes ${ }^{5}$. As patentes são consideradas importantes ferramentas e instrumento bastante eficaz no apoio à tomada de decisão, tendo em vista seu conteúdo informacional, que permite investigar patentes existentes e emergentes e suas reivindicações. Com isso, possibilitando identificar tecnologias relevantes, parceiros, nichos de mercados, inovações incrementais e movimentos da concorrência, tais como investimentos, gestão de processos, gestão de produtos e/ou serviços, novas linhas de pesquisa e desenvolvimento, fusões e aquisições, dentre outras.

O monitoramento político-econômico tem como finalidade observar aspectos voltados à legislação, cultura, política, sociedade, economia, que de alguma forma, se relacionam ou interferem na trajetória e estratégias da organização, impactando nos negócios.

O monitoramento financeiro busca conhecer os mercados, os clientes e a avaliação de suas necessidades, e poder aquisitivo; os fornecedores, sua estratégia de lançamento de novos produtos; o perfil da mão de obra do ramo de negócio e na cadeia de valor

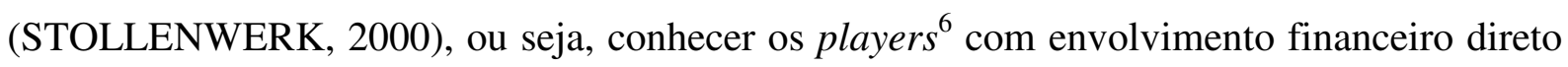
e indireto no seu ambiente de negócios.

\footnotetext{
${ }^{4}$ Forças de Porter foi um modelo concebido por Michael Porter, em 1979, e destina-se à análise da competição entre empresas/organizações. São consideradas cinco forças competitivas, rivalidade entre os concorrentes, poder de negociação dos clientes, poder de negociação dos fornecedores, ameaça da entrada de novos concorrentes e ameaça de produtos substitutos.

${ }^{5}$ Patente é um documento que representa uma concessão pública, conferida pelo Estado, que garante ao seu titular a exclusividade ao explorar comercialmente a sua criação ou descoberta.

${ }^{6}$ Os atores envolvidos ou participantes do ambiente de negócio.
}

InCID: R. Ci. Inf. e Doc., Ribeirão Preto, v. 2, n. 2, p. 125-144, jul./dez. 2011. 
O monitoramento é, antes de tudo, a prospecção de oportunidades de desenvolvimento, tanto no interior como no exterior da organização. Essas oportunidades nunca são de uma única natureza, tecnologia, por exemplo, mas, também, de sinergia, de novas estratégias e de aberturas de novos espaços. O publico visado não é, necessariamente, o que está ligado à informação tecnológica (pesquisadores, engenheiros, técnicos, os quais, devido à sua própria função na organização, devem conhecer a evolução da pesquisa e dos desenvolvimentos). Assim, a organização deve abandonar seu isolamento funcional por uma associação de competências e de conhecimento, todavia, também informações de acompanhamento político, jurídico, financeiro, etc., são necessárias para decidir suas orientações estratégicas. Isso, pois, a informação tecnológica é indissociável da informação econômica e social, dos movimentos estratégicos dos grupos internacionais, das mudanças de comportamentos e dos mercados financeiros. O monitoramento não pode mais ser exclusivamente científico, tecnológico, financeiro, político- econômico, mas abordar todos os elementos que compõem o ambiente organizacional interno e externo.

Portanto, o monitoramento é a investigação do ambiente em busca de informação pertinente, envolvendo vigiar, observar, verificar e manter-se a par dos desenvolvimentos dentro da área ou negócio estabelecido, podendo ser focalizada ou contextual, reduzindo a probabilidade da organização ser surpreendida.

\section{Fundamentos e elementos básicos da inteligência competitiva}

A origem da IC foi com a Guerra Fria nos anos 50, e nos anos 80 e 90, com a globalização da economia, com a crescente oferta de informação e a competição acirrada, o que gerou grande crescimento para a IC. Nos anos 80 surgem os estudos de Michael Porter do Massachusetts Institute of Technology (MIT), dos Estados Unidos, e Jan Herring, da empresa Motorola. Em 1986, foi criada a Society of Competitive Intelligence Professionals (SCIP) ${ }^{7}$, uma sociedade internacional de profissionais que atuam com IC. O grande crescimento mundial, principalmente com o desenvolvimento da literatura sobre o assunto, ocorreu nos anos 90 e também a vinda para o Brasil, inclusive com o surgimento da representação da SCIP no Brasil. Nos anos 2000, ocorreu o efetivo crescimento, com a criação da Associação Brasileira dos Analistas de Inteligência Competitiva (ABRAIC) ${ }^{8}$ e da Sociedade Brasileira de

\footnotetext{
${ }^{7}$ www.scip.org

${ }^{8}$ www.abraic.org.br
}

InCID: R. Ci. Inf. e Doc., Ribeirão Preto, v. 2, n. 2, p. 125-144, jul./dez. 2011. 
Gestão do Conhecimento (SBGC) ${ }^{9}$, e também a divulgação da aplicação de IC em diversos casos organizacionais no Brasil, como: Petrobrás, Banco do Brasil, Embraer, Rhodia, Shell, Ericsson, AT\&T, Vivo, entre outras.

A importância da IC é destacada por diversos fatores como:

- Globalização, crescente oferta de informação e competição acirrada (necessidade de antecipação e visão de futuro);

- Crescente necessidade das organizações por informação analisada para inovar (aumento da velocidade de inovação e das novas tecnologias);

- Necessidade de métodos e ferramentas para aumento da eficiência na produção da informação analisada;

- Busca de resultados rápidos, aumento do interesse em descobrir e antecipar os desenvolvimentos dos concorrentes.

Assim, a IC passou a ser incorporada nos processos de tomada de decisão das organizações públicas e privadas.

Para reforçar a importância de métodos ou técnicas como a IC, observando-se o cenário organizacional desses últimos anos, das 500 maiores empresas do mundo na década de 70, segundo a revista Fortune, 411 fecharam ou foram vendidas. No Brasil, das 500 maiores empresas listadas pela Revista Exame, em 1975, apenas 32\%, ou 162 empresas, constavam na lista em 1995. Isso, leva ao questionamento, a respeito do que aconteceu, o que poderia ter sido feito. Assim, uma das respostas pelo que ocorreu poderia ser que essas empresas, sem adequadas informações, não tomaram boas decisões. Muitas dessas empresas desapareceram e ficaram sem "rumo". Dessa forma, surge os desafios da IC, fazer chegar a informação correta para a pessoa certa, no lugar adequado, no momento exato e com tecnologia adequada, demonstrando a alta administração e a todos os membros da organização, idéias repetidas por muitos na literatura e principalmente no meio empresarial. Com isso, a IC deve poder crescer dentro das organizações e adaptar-se às mudanças que virão, mesmo que não se conhece quais são elas.

A inteligência pode ser empregada em diferentes contextos: empresarial, políticas públicas, social, senso comum, educação, fiscal, militar, segurança pública, dentre outros. No contexto empresarial existem os níveis de influência da estrutura organizacional, constituindo os níveis estratégico, tático e operacional. Esses níveis hierárquicos são geralmente representados por uma pirâmide, em que a base representa o nível operacional que consiste do

\footnotetext{
${ }^{9}$ www.sbgc.org.br
}

InCID: R. Ci. Inf. e Doc., Ribeirão Preto, v. 2, n. 2, p. 125-144, jul./dez. 2011. 
conjunto de atividades e decisões cotidianas associadas ao funcionamento da empresa, seu dia a dia. O nível tático, gerencial ou intermediário tem como papel traduzir e harmonizar as decisões estratégicas com as práticas operacionais. O nível mais alto da pirâmide é o estratégico; ele é diretivo, formado pela alta administração ou diretoria, onde são tomadas as decisões estratégicas, que definem os rumos da empresa.

Os dados, as informações e a inteligência permeiam todos os níveis organizacionais e no processo de transformação de dado em informação, e evoluindo para a inteligência, é importante frisar que toda informação estará sempre sujeita à interpretação do responsável pela decisão, para o qual ela foi preparada, em qualquer dos níveis da organização, pelo fato de existirem vários fatores de influência nesse processo, como: modelos mentais, vieses, percepções, conhecimentos, experiência, etc.

Atualmente a IC pode ser definida, de maneira ampla, como um processo de aprendizado, motivado pela competição, e baseada na informação que fortalece as estratégias da organização a curto, médio e longo prazo.

De acordo com a ABRAIC, IC é definida como um processo informacional proativo que conduz à melhor tomada de decisão, seja ela estratégica ou operacional e como um processo sistemático que visa descobrir as forças que regem os negócios, reduzir o risco e conduzir o tomador de decisão a agir antecipadamente, bem como proteger o conhecimento gerado.

A SCIP define a IC como um programa sistemático e ético para coletar, analisar e gerenciar informação externa, que pode afetar os planos, decisões e operações da empresa.

Fuld (1994) define a IC como a informação analisada para tomada de decisão e o processo analítico que transforma informação desagregada em conhecimento relevante, acurado e útil sobre a posição, performance, capacidades e intenções dos competidores.

Segundo Kahaner (1997), a IC explicita a informação analisada para tomada de decisão, visando à obtenção de uma vantagem competitiva.

Gilad (2000) define a IC como uma atividade de monitoramento do ambiente externo à empresa para obter a informação relevante à tomada de decisão.

Herring (1997) parte do conceito de que a IC é o conhecimento dos ambientes externo e interno da organização, aplicado ao processo de tomada de decisão, objetivando o posicionamento e vantagem competitiva.

Segundo Tarapanoff (2001), a IC é um processo sistemático que transforma pedaços esparsos de dados em conhecimento estratégico. É a informação sobre produtos específicos e 
tecnologia. Também é MI externas que afetam o mercado da organização, como por exemplo, a informação econômica, regulatória, política e demográfica.

Para Valentim (et. al., 2003), o processo de IC investiga o ambiente externo à organização, bem como diagnostica o ambiente interno organizacional, com o propósito de descobrir oportunidades e reduzir os riscos, visando o estabelecimento de estratégias de ação a curto, médio e longo prazo.

Com Miller (2002) o processo de IC se inicia de uma necessidade que a organização detecta ao se deparar com problemas complexos e relacionados principalmente à falta de informação, relativa tanto ao ambiente interno como o externo.

$\mathrm{O}$ realce feito a todas essas definições e compreensões da IC na literatura, que parecem ser similares ou complementares, possibilitam registrar que a IC é uma maneira de agir e pensar, que conduz a organização a:

- Criar e manter vantagem competitiva;

- Antecipar: descobrir, desenvolver e distribuir a tempo a informação adequada;

- Utilizar meios éticos e legais.

Assim, na essência, o que as organizações modernas realmente precisam são de formas de gerenciar as mudanças. Isso não pode ser feito sem uma maneira de identificá-las. Para responder a essas mudanças, o que os gestores procuram é um processo que dê a habilidade de responder a uma larga quantidade de questões relacionadas aos seus negócios ou ao seu ambiente de atuação.

Portanto, IC é um modo de (adaptado de Fuld) ${ }^{10}$ :

- Alertar antecipadamente ameaças e oportunidades;

- Monitorar e avaliar movimentos dos competidores;

- Alavancar o desenvolvimento da empresa;

- Estar entre as melhores empresas;

- Apoiar a direção da organização;

- Olhar para fora;

- Combinar os prazos (de curto a longo prazo);

- Um modo de vida, um processo.

No dia a dia das organizações, fora e dentro da organização, o ambiente é uma grande arena de informações, na qual pessoas, objetos e organizações emitem, recebem e criam uma

\footnotetext{
${ }^{10}$ Adaptado de www.fuld.com/whatCI.html

InCID: R. Ci. Inf. e Doc., Ribeirão Preto, v. 2, n. 2, p. 125-144, jul./dez. 2011.
} 
cascata constante de sinais e mensagens. Da perspectiva da informação, cada mudança ou desenvolvimento no ambiente externo, gera sinais e mensagens. A organização precisa estar atenta a esses sinais, pois alguns deles podem ser fracos, outros confusos, e outros pouco indicativos de mudanças, mas devem ser considerados.

Observa-se a vasta abrangência da IC, podendo ser: tecnológica, econômica, concorrencial, ambiental, política, social, etc.

Mas, as funções básicas da IC envolvem pesquisas, criação e manutenção de redes de relacionamento de pessoas e organizações, estruturação de equipes para trabalhar com a informação, capacitar gestores para controlar, conduzir e absorver o processo, bem como liderar sua estrutura humana de apoio na organização.

Assim, a IC é trabalho em equipe, voltada para a competitividade, para a sobrevivência e desenvolvimento dos indivíduos, das organizações, das regiões e países.

$\mathrm{Na}$ aplicação da IC, parte-se da informação disponível, que tem as características de ser abundante, incompleta, duvidosa, pública (aberta), confusa, morosa. Trabalhando essa informação disponível, chegamos à informação necessária, produto da IC, com a característica de ser sintética, completa, confiável, confidencial, precisa e rápida. As informações provenientes das diversas fontes de informação (formais e informais) como documentos, bases de dados, jornais, livros, contatos telefônicos, especialistas, etc. são integradas e filtradas (com métodos e ferramentas) com vista ao que se quer obter para responder a uma determinada necessidade da organização. Assim, obtêm-se a informação adequada por meio de, por exemplo, relatório sintético, que conduzirá as melhores decisões para alavancar a competitividade.

Assim, os principais objetivos da IC envolvem coletar informações internas e externas da organização; ler e resumir artigos de revistas e jornais; realizar pesquisas em banco de dados on-line; interagir com pessoas da organização; analisar e sintetizar informações; preparar relatórios periódicos; propor inovações a direção e responder a questões pertinentes. O processo de Inteligência se desenvolve em ciclo. A Figura 2 mostra o ciclo de IC. Esse ciclo de inteligência é composto por várias etapas ou fases como: identificação de necessidades, planejamento, coleta e armazenagem, tratamento, análise e síntese, disseminação e avaliação.

A identificação de necessidades é a primeira fase do processo de IC e abrange o diagnóstico, as oportunidades e a contextualização relativa ao tema focalizado. A partir da definição do objetivo a que se destina o estudo, a contextualização deve incluir a caracterização do domínio de conhecimento e terminologias pertinentes ao tema. Nesta etapa, InCID: R. Ci. Inf. e Doc., Ribeirão Preto, v. 2, n. 2, p. 125-144, jul./dez. 2011. 
diversas fontes são consultadas, tais como: especialistas da área, handbooks, classificação de patentes [OMPI, 1995], entre outras, para permitir uma visão abrangente sobre o tema. Com a grande quantidade das múltiplas fontes disponíveis, a etapa de planejamento compreende a avaliação e a seleção das principais fontes pertinentes ao tema, nas áreas científicas, tecnológica, técnica, de patentes de normas, técnico-econômica, jurídica, geográfica, de meio ambiente, comercial, entre outras, quanto ao seu conteúdo, à recuperação de documentos e suas limitações. Também compreende o planejamento das ações necessárias para a realização das etapas subseqüentes. A fase de coleta de informações abrange informações informais e formais, em papel ou eletrônicas, e requerem uma estratégia de busca elaborada. O domínio da forma de acesso a cada tipo de informação é de fundamental importância nesta fase. A fase análise da informação compreende o tratamento e a análise propriamente dita das informações disponíveis de forma eletrônica, usando ferramentas para facilitar esta fase e complementadas com informações de documentos em papel e de especialistas. Nessa fase são utilizados softwares que possibilitam filtrar e segmentar a informação, baseados em tratamentos bibliométricos e estatísticos, sendo integralizados em cadeia para tratar automaticamente a informação (QUONIAM, et al., 1993). Esses softwares são específicos e existem alguns, por exemplo: Infotrans, para reformatação de dados; VantagePoint, Matheo, Dataview e Matrisme, para análise bibliométrica; Statística para análise estatística; Idealist e Folio Views, para criação de bases de dados; Excell, para planilha de cálculos e o Word, para a elaboração de textos. A combinação desses softwares permite a construção automática de tabelas, gráficos, além da reformatação, estruturação matricial dos dados e a associação dos dados através de redes (BOUTIN, 1997). 


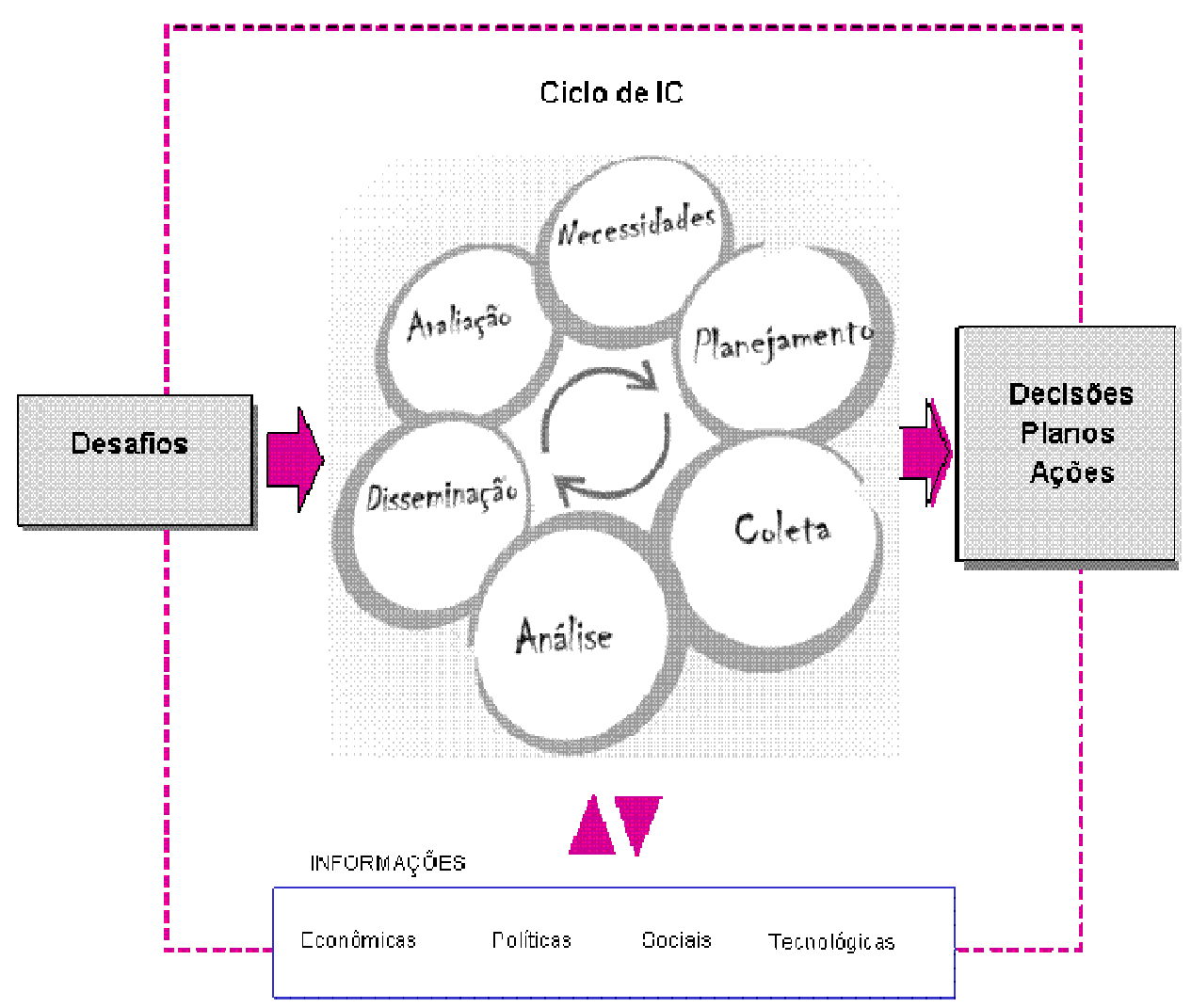

Figura 2 Ciclo da Inteligência Competitiva. Fonte: adaptado (NIT, 2004)

$\mathrm{Na}$ fase de disseminação são disponibilizadas informações de diversas formas, compreendendo a construção de mapas tecnológicos, de atores, de fontes, trajetórias e árvores tecnológicas, visando a identificação de tendências e características de design dominante, tecnologias emergentes e outros aspectos relevantes para o tema focalizado, e de acordo com as necessidades identificadas no início do processo. A fase que finaliza o ciclo compreende a avaliação e a atualização das informações ao longo do tempo e a revisão e ajuste das necessidades focalizadas. Convém lembrar que o rápido surgimento de novas tecnologias, e a obsolescência de outras, faz com que o monitoramento ou atualização seja cada vez mais importante.

Quando se utiliza ou aplicar a IC em uma organização, um fator importante a ser considerado, é que se tenha ou se fortaleça as redes de relacionamento do ambiente interno e externo da organização. A organização e seus fluxos informacionais provenientes do ambiente interno corroboram com a IC no sentido de fortalecerem a integração com os fluxos informacionais do ambiente externo da organização.

Esses fluxos de informação internos e externos de uma organização são potencializados pelo uso e aplicações de TIC, que, muitas vezes, são analíticas visando gerar InCID: R. Ci. Inf. e Doc., Ribeirão Preto, v. 2, n. 2, p. 125-144, jul./dez. 2011. 
os futuros prováveis, auxiliando a organização a antecipar ações. A evolução das TIC envolve desde sistemas transacionais a aplicações analíticas, considerando o passado e o futuro, como forma de motivar os gestores e até especialistas das novas possibilidades de uso de ferramentas para fortalecer a IC, já que esta é suportada pelos recursos de TIC. Alguns exemplos de ferramentas utilizadas e integradas a outros aplicativos, são:

- TextMining: dtsearch, Smart TextMiner, DataSet for MSWord;

- DataMining: Excalibur, RetrievalWare, Oracle Darwin;

- DataWarehousing: Oracle Internet BI, Informix I-SPY;

- Mapeamento do Conhecimento: MSExchange, TheBrain.com;

- CRM: Siebel Applications, IntelligentCRM;

- Benchmarking: desenvolvimento interno, benchmarkindex;

- GroupWare/Workflow: MSExchange, Documentun;

- Agentes Inteligentes: Copernic, Kengi, TextWise

Para a implementação de IC há necessidade de uma visão estratégica, que envolve a habilidade para extrair por completo a informação latente nos dados. A necessidade de definir o alcance do processo, incluindo a habilidade de propagação das informações para todos os envolvidos e de diferentes formas, por exemplo com Internet e Intranet. E, com certeza, a questão da segurança, envolvendo a habilidade de garantir sigilo à informação.

Assim, muitos são os desafios a serem vencidos na implementação da IC, principalmente a necessidade de manter compromisso e envolvimento com a alta administração organizacional. Olhar além dos concorrentes, quando se pensa em IC. Lembrar que a maior parte das informações encontra-se dentro das próprias organizações/empresas, ou seja, com as pessoas.

\section{Considerações finais}

O MI e a IC se mostram chave para as organizações obterem vantagens competitivas. Principalmente no entendimento e identificação das forças que orientam o futuro. É necessário antecipar e compreender o percurso das mudanças; vale ressaltar que orientação e subsídio são fundamentais no processo de tomada de decisão em ciência, tecnologia e inovação. Além de subsidiar decisões relativas ao estabelecimento de prioridades em 
pesquisa, desenvolvimento e inovação, fortalecendo a gestão de risco das inovações tecnológicas, melhorando significativamente a competitividade de produtos e processos.

A efetiva aplicação da IC se deu com a crescente necessidade das empresas por informação analisada para inovar e conquistar novos mercados; a necessidade de métodos e ferramentas para aumento da eficiência na produção da informação analisada; a busca de resultados rápidos; aumento do interesse em descobrir e antecipar os desenvolvimentos dos concorrentes, e a disputa entre países por desenvolvimento.

Assim, as principais aplicações típicas da IC nas organizações são no planejamento (estratégico, marketing, etc.), fusões, aquisições e alianças, pesquisa e desenvolvimento, antecipação de ações e mudanças do ambiente organizacional interno e externo, monitoramento e antecipação de movimentos dos clientes, concorrentes, reguladores. Com isso, obtendo vantagens táticas e de negociação, pois IC é, usando uma metáfora, a arte do caçador, é necessário seguir os rastros.

\section{Referências}

BORGES, M. E. N. A informação como recurso gerencial das organizações na sociedade do conhecimento. Ciência da Informação, Brasília, v. 24, n. 2, 1995.

BOUTIN, E. Information for engineers: from theory to practices. Activity Report. CRRM/Marseille, França, 1997.

CHIAVENATO, I. Introdução à teoria geral da administração. 2 ed. Rio de Janeiro: Campus, 2000.

CHOO, C.; AUSTER, E. Environmental scanning: acquisition and use of information by managers. Inc. For the American Society for Information Science, 1993.

DAVENPORT, T. H. Ecologia da informação. São Paulo: Campus, 2001.

FERREIRA, A. B. H. Novo Aurélio século XXI. São Paulo: Nova Fronteira, 2002.

FULD, L. M. The new competitor intelligence: the complete resource for finding, analyzing and using information about your competitors. John Wiley \& Sons, 1994. 482 p.

GILAD, B. An ad hoc, entrepreneurial CI Model. Competitive Intelligence Magazine, v.3, n. 4, p. 33- 39, 2000. Disponível em:

<http://www.scip.org/news/cimagazine_article.asp?id=165>. Acesso em: 30 set. 2011

HERRING, J. Producing CTI that meets senior management's needs and expectations. In: SCIP Competitive Technical Intelligence Symposium. Boston: SCIP, 1997. 
KAHANER, L. Competitive intelligence: how to gather, analyze, and use information to move your business to the top. Touchstone: New York, 1997.

MILLER, J. P. O nascimento e o crescimento do seu processo de inteligência: fatores comportamentais, culturais e estruturais. In: O milênio da inteligência competitiva. São Paulo: Bookman, 2002. p. 53-65.

MORESI, E. A. D. Inteligência organizacional: um referencial integrado. Ciência da Informação, Brasília, v. 30, n. 2, p. 35-46, maio/ago. 2001.

NAISBITT, J.; ABURDENE, P. Megatrends 2000. São Paulo: Amana-Key, 1990. p. 22-26, p.53-56, p. 61-62.

\section{NÚCLEO DE INFORMAÇÃO TECNOLÓGICA (NIT). Manual de inteligência competitiva. 2004.}

ORGANIZAÇÃO MUNDIAL DA PROPRIEDADE INDUSTRIAL (OMPI). IPC: class user`s guides. Version 2.1. Genebra, 1995. p. 57

QUONIAM, L. HASSANALY, P. BALDIT, P. ROSTAING, H. DOU, H. Bibliometric analysis of patent documents for R\&D management. Research Evaluation, v. 3, n.1, p.13-18, 1993.

STOLLENWERK, M. F. L. Implantação de sistemas de inteligência competitiva: abordagem corporativa. Revista de Biblioteconomia de Brasília, Brasília, v.23/24, n. 4, p. 455-472, 2000.

TARAPANOFF, K. Técnicas para tomada de decisão nos sistemas de informação. Brasília: Thesaurus, 1995.

(Org.). Inteligência organizacional e competitiva. Brasília: Ed. da UnB, 2001.

VALENTIM, M. L. P. et al. O processo de inteligência competitiva em organizações.

DataGramaZero, v. 4, n. 3, jun. 2003. Disponível em:

<http://www.datagramazero.org.br/jun03/F_I_art.htm>. Acesso em: 30 set. 2011.

WEBSTER, F. The changing role of marketing in the corporation. Journal of Marketing, v. 56, p. 01-17, 1992.

Artigo submetido em: 31 out. 2011

Artigo aceito em: 30 nov. 2011 